\title{
An Empirical Analysis of Communication on Trust Building in Virtual Teams
}

\author{
Makoto Shinnishi' ${ }^{1}$, Kunihiko Higa ${ }^{2}$ \\ ${ }^{1}$ Graduate School of Innovation Management, Tokyo Institute of Technology, Tokyo, Japan \\ ${ }^{2}$ Department of Social and Human Sciences, Tokyo Institute of Technology, Tokyo, Japan \\ Email:shinnishi.makoto@gmail.com,khigacrafttitechacjp@gmail.com
}

How to cite this paper: Shinnishi, M. and Higa, K. (2018) An Empirical Analysis of Communication on Trust Building in Virtual Teams. Journal of Service Science and Management, 11, 278-296.

https://doi.org/10.4236/jssm.2018.112020

Received: March 23, 2018

Accepted: April 25, 2018

Published: April 28, 2018

Copyright (c) 2018 by authors and Scientific Research Publishing Inc. This work is licensed under the Creative Commons Attribution International License (CC BY 4.0).

http://creativecommons.org/licenses/by/4.0/

\section{cc) (i) Open Access}

\begin{abstract}
This research aims to analyze the communication on trust building in virtual teams. Ten teams consisting of three workers (an editor, a designer, and a coder) were asked to create a sample web page in one week. All workers were in remote environment and a text-only communication tool was provided to all teams. In addition, five teams could use a non-text communication tool through which one can see other member's situation with a web camera image and a short text message. All communication logs were collected and classified into three types: formal communication, informal communication, and awareness communication. All participated workers answered the questionnaire about trust before and after the task was completed. The analysis results based on the questionnaire and communication log data are discussed at the end. The result shows the use of non-text communication tool did not affect trust building; however, amount of awareness communication affected trust building. Log-in to the communication system at the same time also affected trust building. The findings of this study showed the tendency of awareness communication helping team building trust in the remote environment.
\end{abstract}

\section{Keywords}

Communication, Trust Building, Virtual Team, Crowd Sourcing

\section{Introduction}

\subsection{Background}

Working online has been increasing with the advancement of information and communication technology (ICT). There is a prediction that one in three people will be hired online by 2020 [1]. Worker style is changing by this situation so that workers process the work as a team without face-to-face meetings (off line). 
This team is called a virtual team. A virtual team has the advantage of being free from geographic boundaries and time restrictions. The team members can join from anywhere in the world. Crowd sourcing furthers this kind of work style. Employers can obtain workers from "crowds" in the world, and virtual teams are made in an ad-hoc but adequately with crowd sourcing. In this virtual team setting, workers typically do not meet each other because of geographic distance.

On the other hand, building and maintaining trust among team members has been an issue for a virtual team. Since trust has a great bearing on team productivity [2], it is considered a critical issue for a virtual team. According to the survey by RW3, $81 \%$ of workers responded that productive activities are difficult in a virtual team without the formation of rapport or trust [3].

In the virtual team, all communication is exchanged using ICT. For that reason, many researches have been conducted to clarify the role of communication in trust building in virtual teams [4]. In these studies, there were two problems. One was that workers were students, and they are subject to simulated work. Another was they could not get a log of complete communication.

The purpose of this study is to examine the effect of communication on trust building in a virtual team using real work settings and with complete communication logs.

\subsection{Definitions}

In this subsection, the definitions of trust, virtual team, communication, and awareness are described.

1) Trust

Simmel and Wolff discussed that trust is what is between ignorance and perfect knowledge [5]. This means that the concept of trust becomes unnecessary if a man fully understands the other party. And in response, Giddens mentioned that trust is a belief that s/he can rely on people and systems for a given series of outcomes and events [6]. Especially trust in personality is built on mutuality consisting of response and involvement.

In this research, we use a definition by Giddens that trust is defined as confidence that we can depend on people for a series of consequences and events, and it is built on mutuality consisting of responses and engagement.

2) Virtual Team

A virtual team is a group of people who work interdependently with a shared purpose across space, time, and organization boundaries using technology [7]. A virtual team is becoming more widespread due to the advancement of ICT.

3) Communication

Communication is the human activity that links people together and creates relation-ships [8]. Communication is classified with text communication and non-text communication. In the text communication, it is categorized into formal communication and informal communication. Fay defined informal communication as voluntary talk that does not have to be sole work or task focused 
[9].

Non-text communication in on-line settings can happen through images from CCD, tone of voice, or even by tangible object [10]. This communication is exchanged passively, i.e., the sender of non-text communication is typically not doing it intentionally. In this research, log-in status and images from CCD are treated as non-text communication. These data can be easily obtained as log data.

4) Awareness

Awareness is an essential concept in the field of CSCW (Computer-Supported Cooperative Work) [11]. Awareness was researched in CSCW because of the lack of this kind of information on an online situation. Dourish and Bellotti featured awareness for activity. They defined awareness as an "understanding of the activities of others, which provides a context for your own activity [12]". Jang defines awareness as processing knowledge about the current status and actions of the various components in a collaborative system [11].

In this study, awareness is defined as "knowledge about the work and worker of current and predicted future status and situation." Awareness by text communication, called "awareness communication," is intentionally exchanged by communicating parties.

\section{Related Works}

In this section, related works about trust, a virtual team, and communication are described. Then problems from related works and hypotheses are discussed at the end of this section.

\subsection{Related Works on Trust}

More transaction costs and opportunity costs are needed when the trust score is low among related parties. The impact of trust on economics was described in the lemon market (cf. [13]). In a low-trust environment, laborious efforts are required for a confidence survey, and more expenditure is required. As another utility of trust, it can avoid the risk [14]. From the organization's point of view, trust is needed for all kinds of organization [2]. For that reason, building trust is "the lubrication that makes it possible for organisations to work" [15].

Yamagishi and Yamagishi researched about general trust and proposed a method to measure how persons tend to trust [16]. They defined general trust as "a belief in the benevolence of human nature in general and thus is not limited to particular objects."

\subsection{Related Works on Virtual Teams}

Building trust is difficult, especially for a virtual team because workers cannot ex-change various information face-to-face. One of the lacking pieces of information is called an honest signal [17]. Watkins argued it is a paradox in the studies of the virtual team, while saying that face-to-face is better in building team 
trust [18]. However, if the worker should do face-to-face communication every time, a virtual team will become a world of fantasy. Trust building without face-to-face is needed for the success of a virtual team.

\subsection{Related Works on Communication}

Rueker and Walker claim that the amount of formal communication is key for formalization of the relationship [19]. They argue that formal communication replaces informal communication. However, informal communication is said to be the key to team work [20] [21]. Weisb and reported on the relationship between the number of sent message and performance [21]. The importance of informal communication for building trust was also discussed by Jarvenpaa and Leidner [4]. They report that the amount of communication affects the degree of trust in global virtual teams, particularly either too much or too little informal communication negatively affect trust building. Ito and Kunifuji claim that the use of non-text communication increases the frequency of text communication [22]. Sakakibara, et al., reported that a non-text communication tool, especially video snapshots, affects the amount of informal communication [23]. Therefore, it can be said that there is a relationship between non-text communication and text communication.

\subsection{Objectives of This Study}

Virtual teams face difficulty in trust building because of a lack of face-to-face opportunity. A lack of face-to-face opportunity will also affect communication among team members, which in turn, may affect trust building. In this situation, communication is the key factor for trust building because team members will be able to build trust only through communication. The objective of this study is to analyze the complete communication log for trust building. However, audio and visual communication logs will not be recorded in this study because they contain many unquantifiable features such as tone of voice, facial expressions, gestures, etc. The analysis of these unquantifiable communications will be left for the future study.

The main objective of this study is to examine the effect of communication and trust building in virtual teams. In order to achieve this objective, influence levels of various aspects of communication are tested. It is said that active communication among team members helps trust building in a team. Therefore, the relationship between communication and trust building and the relationship between text communication and non-text communication in virtual teams are analyzed. Lastly, for the relationship between non-text communication and trust building, the group without a non-text communication environment and the group with a non-text communication environment are compared.

In this study, experiments will be conducted in the situations close to a field experiment. In the case of laboratory experiments, students are often used as experimental subjects instead of workers. In such case, motivation for work, 
communication style, and building trust may be different from the actual field environment. In this experiment, we will hire anonymous workers to form virtual teams and to work with provided communication tools through which complete communication logs can be recorded. Thus trust building under conditions close to the actual field environment will be observed.

\subsection{Hypotheses}

Three main hypotheses with six sub-categorized hypotheses are formed as shown in Figure 1. Those are:

H1: communication promote trust building

It is expected that trust will be built through communication. For this hypothesis, total text communication, formal communication, informal communication, and awareness communication will be examined.

H1.1: communication promote virtual teams in building trust

Amount of communication is expected to affect trust building.

H1.2: formal communication promote virtual teams in building trust

Teams with a lot of formal communication are expected to have more trust than teams with less formal communication.

H1.3: informal communication promote virtual teams in building trust

High trust score teams are expected to exchange more informal communication than low trust score teams.

H1.4: awareness communication promote virtual teams in building trust

A high trust score group is expected to exchange more awareness communication than the low trust score group.

Not only the direct communication but also knowing the situation of other members may affect the trust building. To examine the effect of the non-text communication available environment for trust building, the following hypotheses and three sub-categorized hypotheses are tested.

$\mathrm{H} 2$ : a non-text communication available environment helps in building trust in virtual teams

The treated group is expected to have a higher trust score than that of the control group.

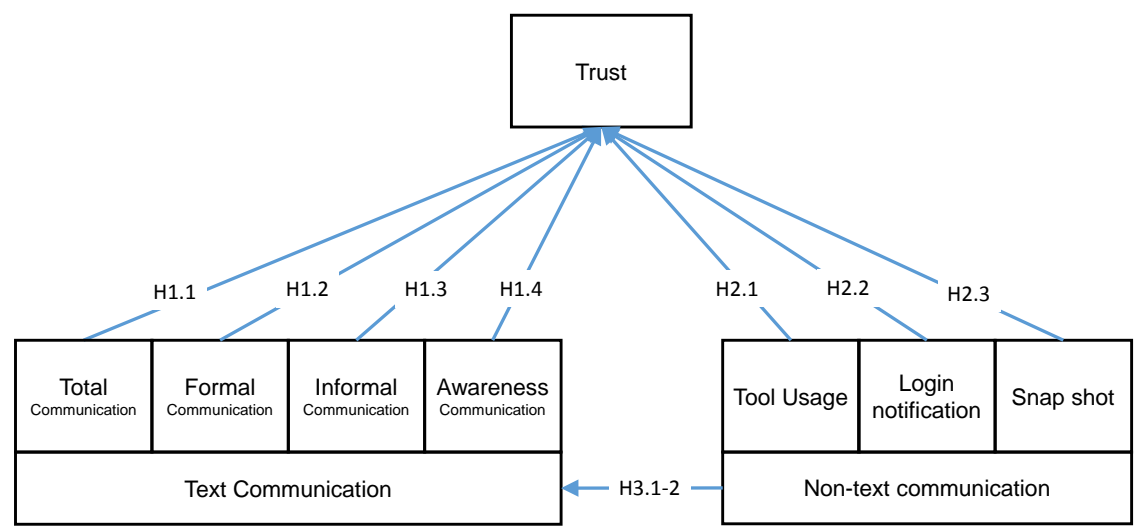

Figure 1. The analysis model for this study. 
H2.1: a non-text communication tool helps virtual teams in building trust

Teams with a non-text communication tool will develop higher trust than that of teams without a non-text communication tool.

H2.2: log-in notification affects building trust

In the treated group, high trust score teams are expected to exchange more log-in notification than low trust score teams.

H2.3: snap shot affects building trust

In the treated group, high trust score teams are expected to exchange more snap shots than low trust score teams.

The provision of awareness leading to an increase in the amount of communication has been reported by Sakakibara et al. [23].

H3: non-text communication available environment leads to more communication

In this study, the effects of two types of non-text communication are examined for the increase of communication.

H3.1: non-text communication tool helps increase communication

The treated group is expected to have more communication than the control group.

H3.2: non-text communication leads to more communication

A positive correlation between the amount of non-text communication and the amount of other communication is expected.

\section{Research Design}

The effect of communication on trust building in virtual teams is the question addressed in this study. However, to know whether or not workers actually used non-text communication before they communicate each other and how non-text communication helps building trust in a virtual team is extremely difficult if it is not impossible. Therefore, in this study, a non-text communication available environment will be provided to several virtual teams, and their communication activities and trust building are compared with those of virtual teams without a non-text communication available environment. Here, a non-text communication available environment will be created by providing an non-text communication support tool (called C-WORK [24]) through which a team member can obtain other members' log-in status, exchange snapshots, and post a short text message on the message board.

Several virtual teams will be formed in order to examine the effect of a non-text communication available environment on communication and trust building in virtual teams. In this section, team forming, data collection, and analysis method will be described.

\subsection{Team Forming}

Editors, designers, and coders will be recruited through a crowd sourcing platform. They will be formed into three-member (one editor, one designer, and one 
coder) teams and asked to create a web site. The task will be performed in telework; therefore, all teams will be virtual teams. Each worker will be assigned to a team so that they have common work time, i.e., team members can communicate in real time if they wish to. If it is possible, the work experience level of workers will be considered for team forming. Formed teams will be assigned into either the group with C-WORK or the group without C-WORK. The former group is the treated group, and the latter one is the control group. Age, gender, and work experience in crowd sourcing will be considered so that the two groups have similar teams.

\subsection{Communication Tools Used}

In this study, all communication between group members during the experiment period (for several weeks) needs to be recorded for the analysis. For this reason, existing communication means such as telephone, email, video conference tool (e.g., Skype) cannot be used. Instead, particular communication tools will be used in this study so that all communication logs will be obtained. They are Group Memory Support System (GMSS) and C-WORK. GMSS is a web-based text communication tool for group communication [25], and this tool will be provided to all participants. GMSS supports team members' asynchronous communication. When a team member posts a message in GMSS, the team members are notified about the posting via email. Team members can exchange messages only through GMSS, since team members do not know each other's email address, and, of course, exchange of private email address will be strictly prohibited. GMSS is the main communication tool for all teams. GMSS also supports synchronous communication with a text-based chat.

In addition to GMSS, a non-text communication tool, called C-WORK, will be provided to treated groups. C-WORK is a web-based non-text communication platform [24]. It has three functions: exchanging members' snapshots, log-in status information, and a short text message board. Snapshots are taken by a worker's built-in PC camera or connected web camera. To protect the privacy of users, the reciprocity concept is applied in C-WORK, i.e., a user can see the other members' picture in C-WORK only when s/he turns on her/his camera. As an additional privacy protection, pictures are shown as if they are looked through a shade. Figure 2 shows the user interface of C-WORK. The picture is automatically updated every minute. A user can also manually update the picture by pressing the "Snapshot" button. Log-in status information is used to know who is logged in now. When the user is logged in, the log-in status is turned to orange and message is turned to "I'm in". Otherwise, the log-in status is displayed in gray and a message is shown as "I'm Out". A short text message is expected to be used for sharing a user's situation such as "I'll be back at 2 p.m. tomorrow." Once a user posts the message, the previous message is deleted, and other users cannot see previous messages. C-WORK provides log-in information, a snapshot, and a message board. The former two items are treated as 


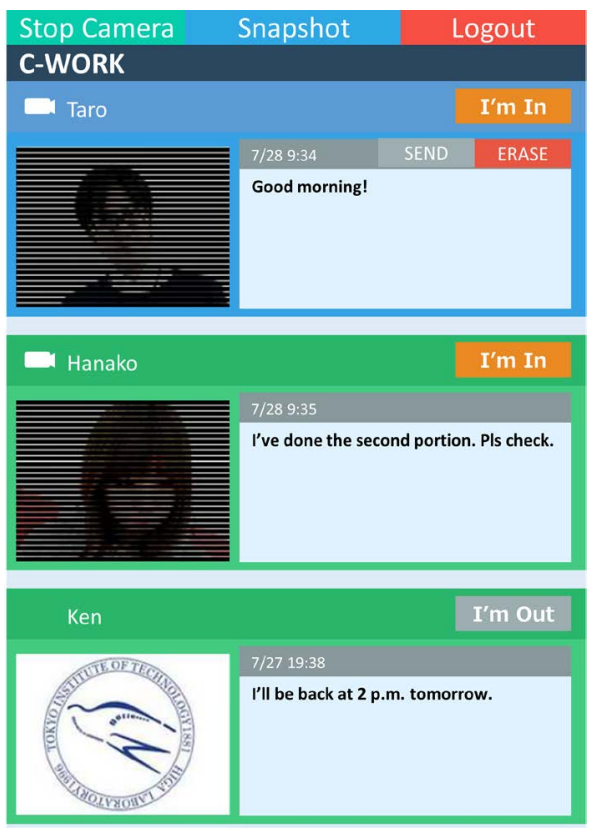

Figure 2. User Interface of C-WORK.

non-text communication and the last one and text messages by GMSS are treated as text communication.

Since all communications between team members will be carried out via provided communication tools during the experiment, complete communication log data will be obtained.

\subsection{Data Collection}

Three types of data used for the analysis in this study are described. Those are survey data, text communication logs, and awareness information logs.

\subsubsection{Survey Data}

In order to collect data about trust, two questionnaire surveys will be conducted. For general trust, the questionnaire developed by Yamagishi and Yamagishi [16] will be answered by all workers before the group work. Table 1 shows the questionnaire about general trust, and each question will be answered in a seven-Likert-scale. This result will be used for team formation so that all teams will start with approximately the same general trust score. After the group work, the trust score for team members will be tested via the survey questionnaire developed by Jarvenpaa and Leidner [4]. Table 2 shows the questionnaire about team member's trust, and each question will be answered in a five-Likert-scale. These questionnaires will be combined after examining the Cronbach's alpha. Then teams will be categorized into two groups based on the trust score of each team, i.e., divide teams into two groups according to the mean trust score of each team. A team with trust score higher than the mean trust score of all teams will be categorized as a high trust group; otherwise, as a low trust group. A t-test will be conducted to see the difference in trust score of these two groups. 
Table 1. Questionnaire for general trust.

\begin{tabular}{cc}
\hline Q1. & Most people are basically honest. \\
Q2. & Most people are trustworthy. \\
Q3. & Most people are basically good and kind. \\
Q4. & Most people are trustful of others. \\
Q5. & I am trustful. \\
\hline
\end{tabular}

Table 2. Questionnaire for team member's trust.

\begin{tabular}{cc}
\hline Q1 & Members of my work group show a great deal of integrity. \\
Q2 & I can rely on those with whom I work in this group. \\
Q3 & Overall, the people in my group are very trustworthy. \\
Q4 I would be comfortable giving the other team members a task or problem which was \\
critical to the project, even if I could not monitor them.
\end{tabular}

\subsubsection{Communication Logs}

Communication log data of GMSS and C-WORK will be examined. Posted text from GMSS, CHAT, and C-WORK will be categorized as text communication. Sentences in text communication will be classified into "Formal communication," "Informal communication," and "Awareness communication" based on the rule defined by Weisband [26]. Table 3 shows the classification of group awareness messages. In this study, the first three awareness types "self-awareness", "availability awareness", and "process awareness" will be classified as "Awareness communication". The "social awareness" will be classified as "Informal communication". Other communication types will be classified as "Formal communication".

Non-text communication includes log-in information and snapshots in C-WORK. Log-in information includes hours, minutes, and seconds. The C-WORK system can capture the information of user's log-in time and logout time. Even when the browser is closed without log out, the system will know the user status because the system checks the browser every 30 seconds. Snapshot information will be captured in a similar manner. The number of snapshots taken will be counted for each user. Since an actual access log is practically unobtainable, each opportunity that other team members can access to the updated information will be counted as substitution for the access log of non-text communication.

\subsubsection{Task and Deliverables}

A sample web site development for the existing research project "Valuation of the Next Generation Unified Communication System" will be the group task assigned in this study. The same set of documents about the project will be provided for all teams, and teams will be asked to complete their sample web site within seven days. Each team will consist of three members: an editor, a designer, and a coder. Each role will be recruited separately, and then available work 
Table 3. Classification of group awareness messages.

\begin{tabular}{|c|c|c|}
\hline $\begin{array}{l}\text { Classification in this } \\
\text { research }\end{array}$ & $\begin{array}{l}\text { Classification by } \\
\text { Weisband [26] }\end{array}$ & Description \\
\hline \multirow{3}{*}{$\begin{array}{l}\text { Awareness } \\
\text { communication }\end{array}$} & self-awareness & $\begin{array}{l}\text { information about what the particular team } \\
\text { member is doing at any given moment }\end{array}$ \\
\hline & $\begin{array}{c}\text { availability } \\
\text { awareness }\end{array}$ & $\begin{array}{l}\text { information about when team members are } \\
\text { available to "meet" through alternate forms of } \\
\text { communication }\end{array}$ \\
\hline & process awareness & $\begin{array}{l}\text { information about setting up and coordinating the } \\
\text { work, deciding who should do what, figuring out } \\
\text { what do to next and when the work is due }\end{array}$ \\
\hline $\begin{array}{l}\text { Informal } \\
\text { communication }\end{array}$ & social awareness & $\begin{array}{l}\text { information about team member relationships, } \\
\text { supporting team members' efforts, and discussing } \\
\text { topics and events unrelated to the topic }\end{array}$ \\
\hline $\begin{array}{c}\text { Formal } \\
\text { communication }\end{array}$ & - & Communication for process their task or work. \\
\hline
\end{tabular}

time, possession of a web camera by each subject, and the general trust score of each subject will be used for team formation. Subjects will be allowed to use only the provided communication tool so that all communication logs can be recorded. All subjects of the competition will be paid 4,000 yen (about \$40) after completion of the task, which includes two questionnaires and the completion of a sample web site. Agreements from all subjects for the use of log data and questionnaire data for the analysis in this study will be obtained before the experiment starts.

\subsection{Analysis Method}

The data collected from the questionnaire related to trust will be consolidated to be a trust score after confirming the internal consistency using Cronbach's alpha.

The text data collected from GMSS, CHAT, and C-WORK will be analyzed sentence by sentence. In this analysis, each sentence will be classified as formal communication, informal communication, awareness communication, or miscellaneous communication, and the first three types of sentences will be actually used for further analysis.

Time data for non-text communication such as $\log$-in/log-out and snapshots will be recorded. With these data, not only each subject's activities but also number of opportunities for other subjects in the same team to access such activity data can be deter-mined. For example, if a snapshot was taken at 21:00 of a particular day by a subject, and his/her team member had log-in to C-WORK at 21:10 of the same day then this team member had an opportunity to access this non-text communication.

Each hypothesis will be tested in the following manner:

Hypothesis H1.1, teams will be categorized into a high trust group and a low trust group according to each team's trust score. The amount of communication will be compared for these two groups using t-test. Amounts of formal, informal, 
and awareness communication for these two groups will also be compared so that hypothesis H1.2 1.4 will be tested.

Hypothesis H2.1 will be tested by comparing the amount of communication between the treated and the control groups. T-test will be used for the comparison.

Hypothesis H2.2 is applicable only for the treated group. The correlation between the mean trust score and the amount of non-text communication, such as log-in time, duration of simultaneous log-in time with other team members, and time of each snapshot taken with log-in time of other team members, will be examined.

Hypothesis H3.1 will be tested by comparing the amount of communication of treated and control groups.

Hypothesis H3.2 is applicable only for the treated group. The amount of non-text communication and the amount of communication will be compared.

\section{Results}

The experiment started with fourteen teams; however, four coders quit during the experiment. Therefore, ten teams completed the task with three members. For the purpose of this experiment, these ten teams were analyzed (five teams with C-WORK), and the analysis results were discussed in this section.

\subsection{Teams Formed for the Experiment}

Ten teams completed the assigned task (five teams for both the treated group and the control group). There were nine female members in the treated group and eight female members in the control group. The average age was 38.1 years for the former group and 39.1 years for the latter group. The work experience in crowd sourcing for the both groups was also similar, as shown in Table 4.

\subsection{Comparison of Two Groups}

Before the analysis of communication log data and trust building results, demographics (gender, age, and job experience in crowd sourcing) of workers in two groups were compared. As shown in Table 4, there was no significant difference found between two groups.

Besides the demographic difference, the difference in general trust score between the two groups was also examined. As shown in Figure 3, the mean of general trust for the treated group was 4.27 and was 4.31 for the control group. No statistically significant difference was found between these groups. In order to test hypotheses, t-test was conducted based on communication log data and questionnaire data. Four trust attributes of each participant obtained from the questionnaire after the work were analyzed. These four attributes were combined to form a single trust score (Cronbach's alpha $=0.951$ ). The mean trust scores of the control group and the treated group were 3.97 and 3.03, respectively. Although the mean trust score of the treated group was higher than that of 
Table 4. Demographics of workers.

\begin{tabular}{|c|c|c|c|}
\hline & & w/C-WORK & w/o C-WORK \\
\hline \multirow{2}{*}{ Sex (headcount) } & Female & 9 & 8 \\
\hline & Male & 6 & 7 \\
\hline \multirow{2}{*}{ Age } & Range & $20-50$ & $20-40$ \\
\hline & Mean & 38.1 & 39.1 \\
\hline \multirow[b]{2}{*}{$\begin{array}{l}\text { Job experience in } \\
\text { crowd sourcing }\end{array}$} & First time & 1 worker & 2 workers \\
\hline & $\begin{array}{c}\text { Number of completed tasks } \\
\text { with rating }\end{array}$ & 3.8 & 5.1 \\
\hline
\end{tabular}

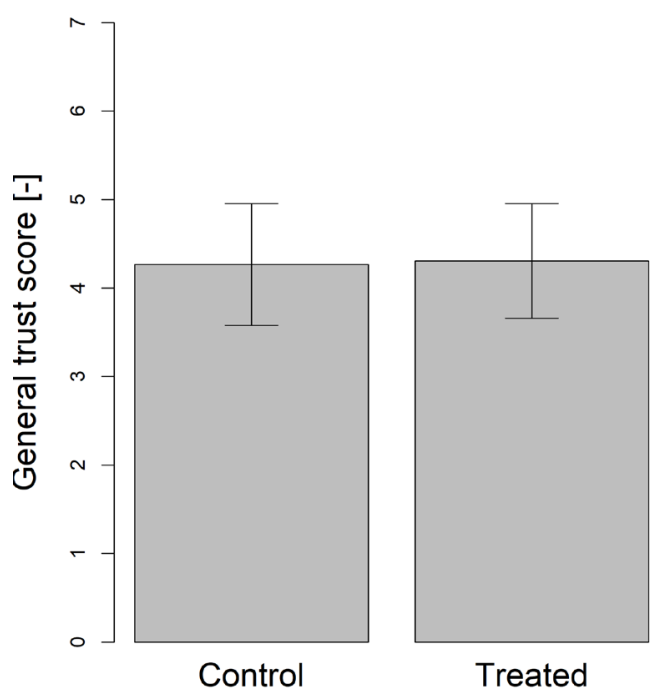

Figure 3. Comparing general trust scores.

the control group, no statistically significant difference was found $(\mathrm{p}=0.113)$. The comparison result of the mean trust scores between these two groups is shown in Figure 4.

Next, the text communications of these two groups were compared. All text communication logs of GMSS, CHAT, and C-WORK were divided into formal communication, informal communication, and awareness communication based on the classification shown in Table 3. Amounts of text communication by the treated group and the control group are shown in Table 5 and Table 6, respectively. Although there was no statistically significant difference, the treated group had twice more awareness communication compared with the control group.

\subsection{Comparison of High Trust Score Team and Low Trust Score Team}

In order to investigate the relationship between communication types and trust building, teams were categorized into a high trust score group and a low trust score group. The mean trust score of all teams was 3.5, Teams with higher trust 
Table 5. Communication channels and types for the treated group.

\begin{tabular}{ccccc}
\hline The treated group & C-WORK & chat & GMSS & Sum total \\
\hline Formal communication & 275 & 472 & 2198 & 2945 \\
Informal communication & 23 & 4 & 0 & 117 \\
Awareness & 120 & 8 & 117 & 245 \\
Sum total & 418 & 484 & 2405 & 3307 \\
\hline
\end{tabular}

Table 6. Communication channels and types for the control group.

\begin{tabular}{cccc}
\hline The control group & chat & GMSS & Sum total \\
\hline Formal communication & 738 & 2044 & 2782 \\
Informal Communication & 37 & 41 & 78 \\
Awareness & 48 & 64 & 112 \\
Sum total & 823 & 2149 & 2972 \\
\hline
\end{tabular}

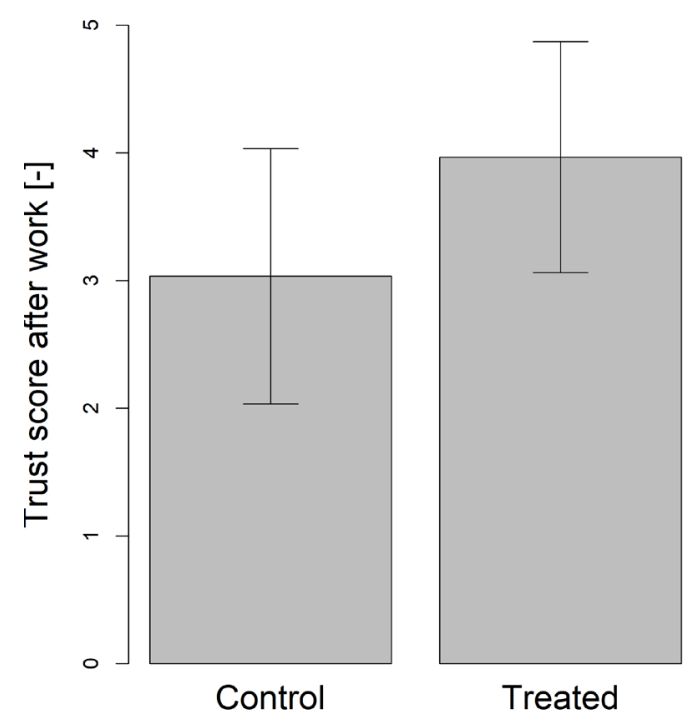

Figure 4. Comparing trust scores after work.

score were categorized into a high trust group, and into a low trust group otherwise. The mean trust score of the high trust score group was 4.25, and 2.75 for the low trust score group, and the difference was statistically significant ( $p=$ 0.002). The comparison result is shown in Figure 5.

To examine the difference between these two groups, amounts of communication of each type were compared. Figure 6 shows the difference of the mean of total communication sentences between two groups. Although there was no statistically significant difference $(p=0.368)$, the high trust score group (726.8) was more communicative compared to the low trust score group (529.4). Figure 7 shows the difference of mean of formal communication between two groups. Again, while there was no statistically significant difference $(p=0.451)$, the high trust score group (650.6) communicated more than the low trust score group 


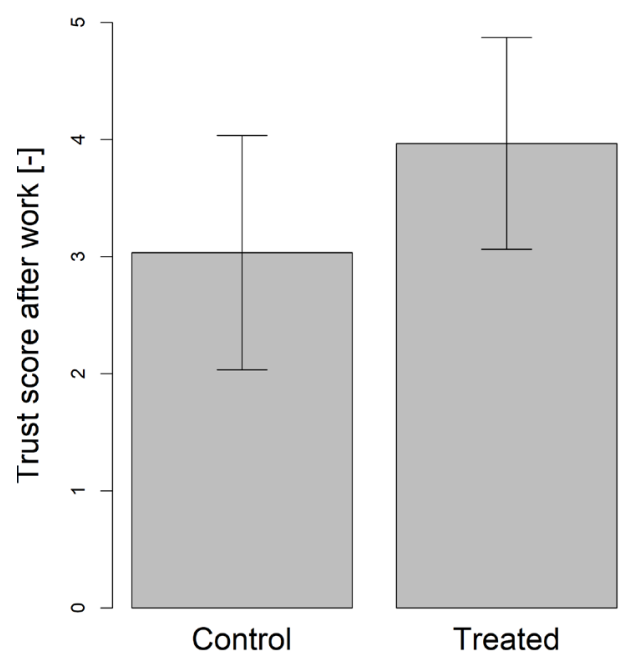

Figure 5. Comparing mean of trust.

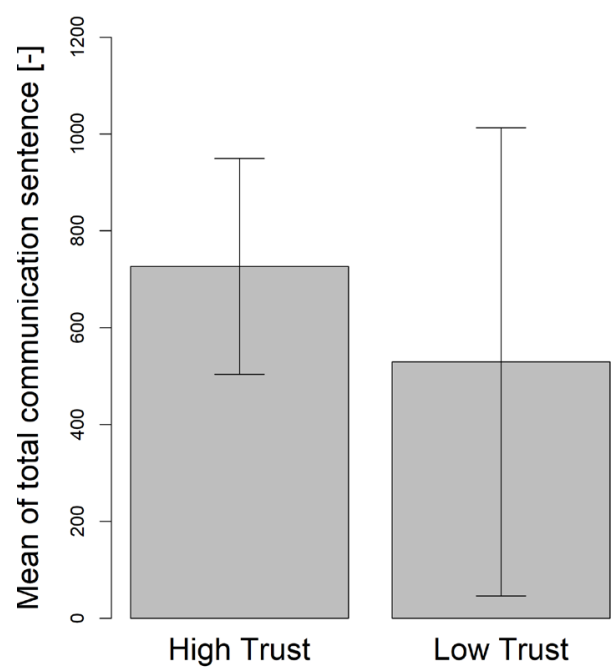

Figure 6. Comparing mean of total communication.

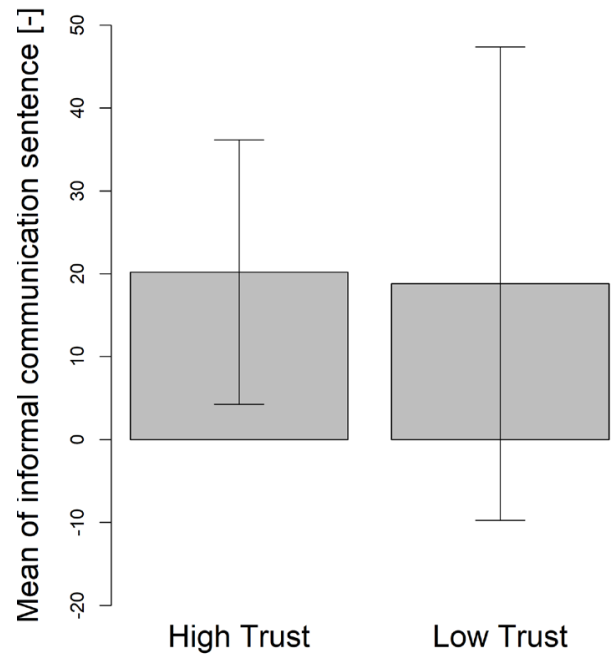

Figure 7. Comparing mean of formal communication. 
(495.2). Figure 8 shows the difference of the mean of informal communication between two groups. Once more, there was no statistically significant difference $(p=0.916)$, but the high trust score group (20.2) sent more informal communication sentences compared to the low trust score group (18.8). Lastly, the difference of the mean of awareness communication between the two groups was examined (see Figure 9). The high trust score group (56.0) sent more awareness messages than low trust score group (15.4), and the difference was statistically significant $(p=0.005)$.

\subsection{Non-Text Communication and Trust}

Using C-WORK, non-text communication such as log-in information and snapshots were shared. Table 7 shows the time spent for non-text communication. The workers in the treated group logged into C-WORK for 488 hours 48 minutes and 29 seconds in total. Workers in the same team logged in at the same

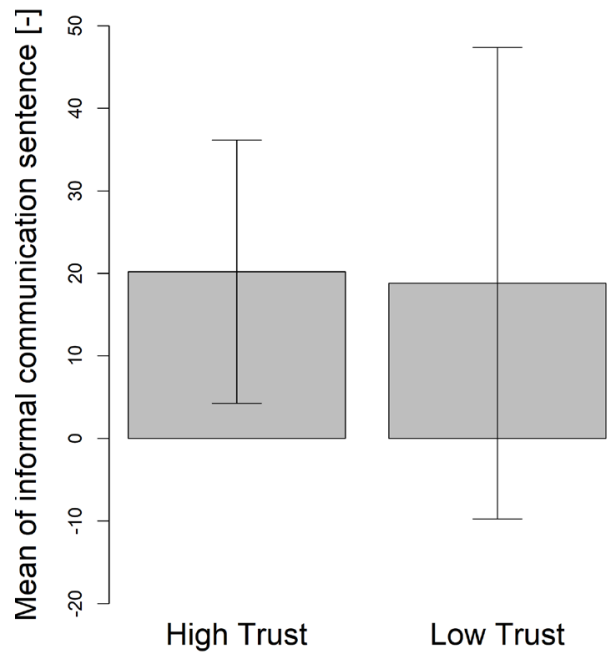

Figure 8. Comparing mean of informal communication.

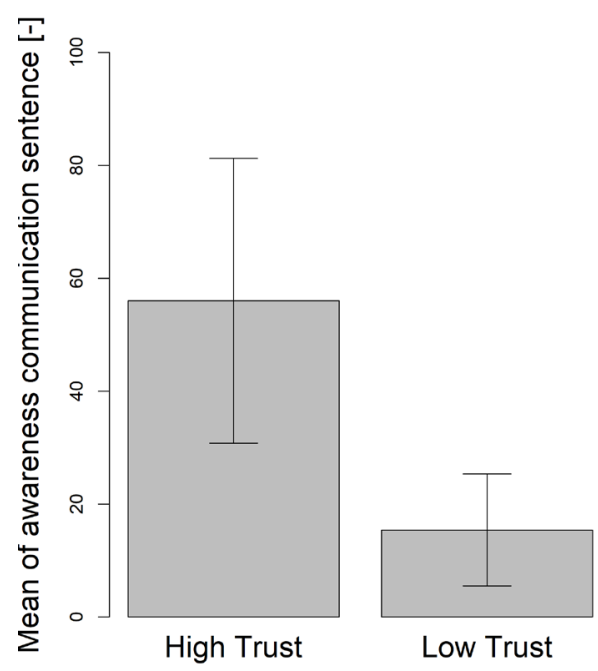

Figure 9. Comparing mean of awareness communication. 
time for 70 hours 41 minutes and 3 seconds in total. Workers shared their snapshots for 23 hours 31 minutes and 18 seconds in total. A snapshot in C-WORK can be viewed by a user only if the user has a CCD camera, and the total log-in time of users with a CCD camera while snapshots were shared by other team members was 3 hours 6 minutes and 57 seconds.

Table 8 shows the correlation between trust and non-text communication. There is a significant correlation between trust and sessions together, i.e., logged into C-WORK at the same time, $(0.669, p=0.034)$. However, there was no significant correlation found between trust and non-text communication factors.

\subsection{Building Trust without Non-Text Communication Tool}

Control groups also had awareness communication such as information about self-situation, communication availability, and work process as shown in Table 3. Therefore, the effect of awareness communication on trust building in control groups was analyzed. Table 9 shows the result. Awareness communication and trust score in control groups were also correlated $(0.529, p=0.043)$, and thus, it can be said that awareness communication positively affects trust building even without a non-text communication tool.

\subsection{Discussion}

The analysis result between the high trust score group and the low trust score group showed that awareness communication positively affected trust building.

A non-text communication tool was expected to help in building trust;

Table 7. Time spent for awareness information.

\begin{tabular}{cc}
\hline & Hours: Minutes: Seconds \\
\hline Total session time & $488: 48: 29$ \\
Session together & $70: 41: 03$ \\
Total camera time & $23: 31: 18$ \\
Camera together & $3: 06: 57$
\end{tabular}

Table 8. Correlation between trust and awareness information.

\begin{tabular}{ccccc}
\hline & Trust & Session & Session Together & Camera \\
\hline Session & 0.578 & 1 & & \\
Session Together & $0.669^{*}$ & $0.890^{* *}$ & 1 & 1 \\
Camera & 0.252 & $0.677^{*}$ & 0.302 & $0.991^{* *}$ \\
Camera Together & 0.159 & 0.604 & 0.206 & \\
\hline
\end{tabular}

Table 9. Correlation around awareness for the control group.

\begin{tabular}{cccc}
\hline & Trust & Other awareness & Other formal \\
\hline Awareness & $0.529^{*}$ & $0.611^{\star}$ & $0.522^{\star}$ \\
\hline
\end{tabular}


however, the result showed only the tendency of a higher trust score for the treated group than the control group. Nevertheless, it appears that a non-text communication tool encourages awareness communication since the treated group had twice more awareness communication than the control group. There was no statistically significant difference between these two groups for any other types of communication.

The analysis of non-text communication indicated that log-in at the same time helps trust building. The previous research reports that non-text communication promotes text communication [23]; however, no significant correlation between trust and non-text communication was found in this study.

Lastly, the result showed awareness communication was strongly correlated with trust building both in control groups and treated groups.

Figure 10 shows the results of the research findings of this study. In this figure, the solid line indicates the hypothesis supported, and the broken line indicates the hypothesis not supported.

\section{Conclusions}

The purpose of this study is to examine the effect of communication on trust building in a virtual team using real work settings and with complete communication logs.

In conclusion, the amount of awareness communication affected trust building among team members. In addition, non-text communication such as log-in at the same time affected trust building. Workers who worked with team members at the same time more and who shared non-text communication more appeared to develop higher trust than those who did less. Therefore, an exchange of more awareness communication seems to affect trust building in a positive manner.

The following five points must be considered before utilizing the findings of this study. First, the sample size of ten teams (five for each group) was small in order to generalize the findings. Second, the findings were also restricted by the task assigned to teams. This study used the web sites design task with three roles

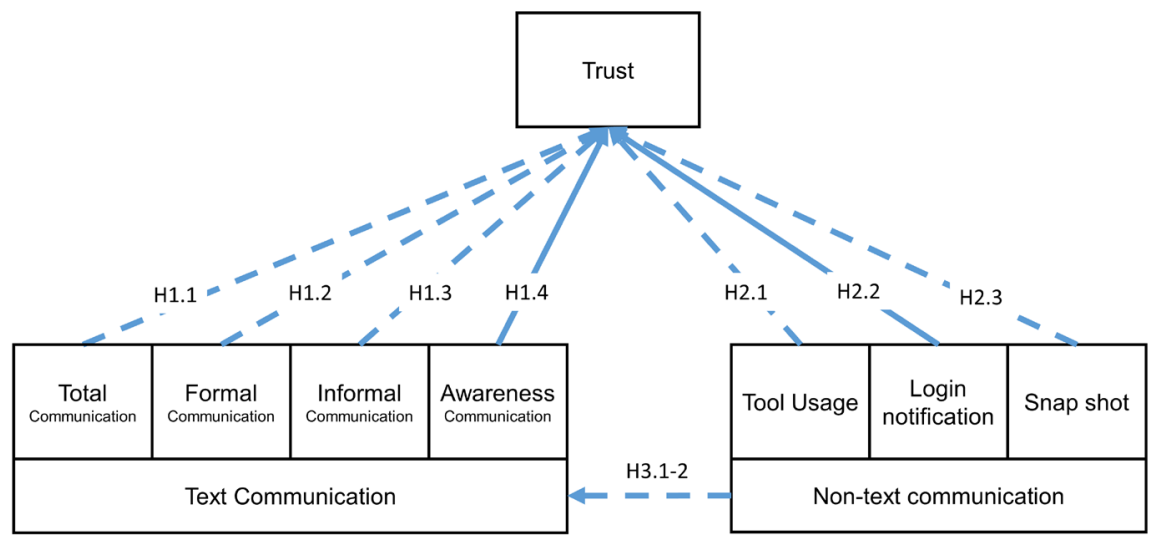

Figure 10. Analysis results. 
for team members (an editor, a designer, and a coder). Third, the period required to complete the task was short. Fourth, voice and video are not handled in non-text communication. Lastly, similar to the third limitation, in order to sink in as a team, it might require more shared work experience. Therefore, a longitudinal study should be conducted with the same team members.

The findings of this study showed the tendency of awareness communication helping team building trust in the remote environment. Additional experiments with more subjects and longer period of time will verify the findings of this research and enable the deepening of knowledge of the role of awareness communication. In the future, it is expected that the relationship between a communication and trust will be made clear, and thus contribute to teamwork development in remote work.

\section{Acknowledgements}

The authors would like to thank Crowd Works Inc. for technical support. This research was made possible by funding from the Oki Electric Industry Co., Ltd.

\section{References}

[1] Swart, G. (2012) Knowledge Stream, Retrieved August 18, 2016.

[2] Karlgaard, R. (2014) The Soft Edge: Where Great Companies Find Lasting Success. John Wiley \& Sons, Hoboken, New Jersey.

[3] Wizard, R.C. (2010) The Challenges of Working in Virtual Teams. Virtual Team Survey Report, USA.

[4] Jarvenpaa, S. and Leidner, D. (1999) Communication and Trust in Global Virtual Teams. Organization Science, 10, 791-815. https://doi.org/10.1287/orsc.10.6.791

[5] Simmel, G. and Wolff, K.H. (1950) The Sociology of Georgsimmel. Vol. 92892, Simon and Schuster, New York, NY.

[6] Giddens, A. (1990) The Consequences of Modernity. Cambridge University Press, Cambridge.

[7] Linpack, J. and Stamps, J. (1997) Virtual Teams: Reaching across Space, Time and Organization with Technology. John Wiley, New York, NY.

[8] Duncan, T. and Moriarty, S. (1998) A Communication-Based Marketing Model for Managing Relationships. Journal of Marketing, 62, 1-13. https://doi.org/10.2307/1252157

[9] Fay, M.J. (2011) Informal Communication of Co-Workers: A Thematic Analysis of Messages. Qualitative Research in Organizations and Management. An International Journal, 6, 212-229. https://doi.org/10.1108/17465641111188394

[10] Ishii, H. and Brygg, U. (1997) Tangible Bits: Towards Seamless Interfaces between People, Bits and Atoms. Proceedings of the ACM SIGCHI Conference on Human Factors in Computing Systems, Atlanta, Georgia, $22-27$ March 1997, 234-241.

[11] Jang, C. (2009) Facilitating Trust in Virtual Teams: The Role of Awareness. Competition Forum. Vol. 7, No. 2, American Society for Competitiveness, 399-407.

[12] Dourish, P. and Bellotti, V. (1992) Awareness and Coordination in Shared Workspaces. Proceedings of the 1992 ACM conference on Computer-Supported Cooperative Work, ACM, New York, 107-114. 
[13] Akerlof, G.A. (1970) The Market for "Lemons": Quality Uncertainty and the Market Mechanism. Quarterly Journal of Economics, 84, 488-500. https://doi.org/10.2307/1879431

[14] Luhmann, N. (2000) Familiarity, Confidence, Trust: Problems and Alternatives. Trust. Making and Breaking Cooperative Relations, 6, 94-107.

[15] Bennis, W. and Nanus, B. (1985) The Strategies for Taking Charge. Harper. Row, Leaders, New York.

[16] Yamagishi, T. and Yamagishi, M. (1994) Trust and Commitment in the United States and Japan. Motivation and Emotion, 18, 129-166. https://doi.org/10.1007/BF02249397

[17] Pentland, A. and Heibeck, T. (2010) Honest Signals: How They Shape Our World. MIT Press, Cambridge.

[18] Watkins, M. (2013) Making Virtual Teams Work: Ten Basic Principles. https://hbr.org/2013/06/making-virtual-teams-work-ten

[19] Ruekert, R.W. and Walker Jr, O.C. (1987) Marketing's Interaction with Other Functional Units: A Conceptual Framework and Empirical Evidence. The Journal of Marketing, 51, 1-19. https://doi.org/10.2307/1251140

[20] Kyriazis, E. and Massey, G. (2008) The Effects of Formal and Informal Communication between Marketing and R\&D Managers during New Product Development Projects. In: Proceedings of the Academy of Marketing Conference, Academy of Marketing, Aberdeen, 1-10.

[21] Alparslan, A.M. and Kılınç, U.K. (2015) The Power of Informal Communication and Perceived Organizational Support on Energy at Work and Extra-Role Behavior: A Survey on Teachers. Journal of Human Sciences, 12, 113-138. https://doi.org/10.14687/ijhs.v12i2.3243

[22] Ito, S. and Kunifuji, S. (2000) Supporting Conversational Awareness in Text-Based Conferencing System. In: 4th International Conference on Knowledge-Based Intelligent Engineering Systems and Allied Technologies, Vol. 1, IEEE, New York, 221-224. https://doi.org/10.1109/KES.2000.885797

[23] Sakakibara, K., Kato, M., Tadokoro, Y. and Miyasaki, T. (2002) “e-Office”, A Communication Support System for Distributed Workers using Media Space. Information Processing in Japan, 43, 2821-2831. (In Japanese)

[24] Numada, T. and Higa, K. (2014) "C-Work", A Web-Based Communication Support System for Distributed Workers. In: 16th Annual Research Congress, Japan Telework Society, Yamagata, 41-45. (In Japanese)

[25] Higa, K. and Yamazaki, Y. (2012) Communication Support and Knowledge Repository in a Distributed Environment: A Proposal and an Evaluation of Group Memory Support System. In: 14th Annual Research Congress, Japan Telework Society, Yamagata, 36-40. (In Japanese)

[26] Weisband, S. (2002) Maintaining Awareness in Distributed Team Collaboration: Implications for Leadership and Performance. In: Hinds, P. and Kiesler, S., Eds., Distributed Work, MIT Press, Cambridge, 311-333. 